\title{
T2a Stage Finding
}

National Cancer Institute

\section{Source}

National Cancer Institute. T2a Stage Finding. NCI Thesaurus. Code C48725.

A general term that refers to a TNM finding of a primary tumor growth beyond the level of in situ cancer, minimal subepithelial invasion, or minimal greatest diameter. The definition of T2a TNM finding depends on the specific type of cancer that it refers to; for example, for kidney cancer it refers to a primary tumor that measures more than $7 \mathrm{~cm}$ but less than or equal to $10 \mathrm{~cm}$ in greatest dimension, and is limited to the kidney; for bladder cancer it refers to a primary tumor that invades the superficial muscularis propria (inner half); for cervical cancer it refers to a primary tumor that invades beyond the uterus but not to the pelvic wall or to the lower third of vagina and there is no parametrial invasion. 